\title{
Pemodelan 2D dan 3D Geolistrik Tomografi untuk Interpretasi Bidang Gelincir dan Arah Aliran Air Pada Struktur Bawah Permukaan Rel Kereta Api di Baturaja, Sumatera Selatan Ahmad Zaenudin ${ }^{1}$, Ilham Dani ${ }^{1}$
}

${ }^{1}$ Teknik Geofisika, Universitas Lampung, Jl. Prof. Sumatri Brojonegoro No. 1, Lampung 35145, Indonesia

Corresponding author.E-mail: ahmad.zaenudin@eng.unila.ac.id Telp: +62-821-82072536, Fax: +62-721-704947

\begin{abstract}
ABSTRAK
Monitoring kondisi bawah permukaan rel kereta api merupakan bagian penting dalam operasional perkeretaapian. Penelitian ini bertujuan untuk mendeliniasi lapisan bawah permukaan rel kereta api yang sering terjadi pergeseran dan longsoran dengan metode geolistrik dipole-dipole secara tomografi. Pemodelan 2D dan 3D geolistrik diterapkan untuk menginterpretasi bidang gelincir dan arah aliran air. Model 2D dapat mengidentifikasi 3 lapisan utama, yaitu lapisan perkerasan tanah di bagian atas, lapisan dengan resistivitas rendah (4-60 Ohm.meter) dan lapisan badrock (100-500 Ohm.meter). Lapisan dengan reistivitas rendah diduga mengandung air sebagai penyebab tanah longsor, dimana bidang batas lapisan ini dialasi oleh bedrock yang berada pada kedalaman antara 5-17 meter yang diduga sebagai bidang gelincir. Model 3D dapat mendeliniasi arah aliran air di bawah permukaan rel kereta api, yaitu berarah Timur Laut - Barat Daya melintasi bagian bawah rel kereta api.
\end{abstract}

Kata Kunci : geolistrik; model 2D dan 3D; bidang gelincir, aliran air 


\begin{abstract}
Monitoring the subsurface conditions of a railroad is an essential part of the railroad system operations. This study intends to delineate the subsurface layers of the railroad tracks, that often shifts and slides, by using the dipole-dipole geoelectric method. The 2D and 3D geoelectric modeling are implemented to determine the sliding surface and the direction of water flow. The 2D model can identify three main layers, which are the soil pavement layer at the top, the layer with low resistivity (4-60 Ohm.meter) and the bedrock layer (100-500 Ohm.meter). A layer with low resistivity is thought to contain water as a cause of the landslides. The boundary plane of this layer is covered by bedrock at a depth of 5-17 meters, which is thought to be a sliding surface. The 3D model can delineate the direction of water flow below the surface of the railroad tracks, i.e., the Northeast-Southwest direction across the bottom of the railroad tracks.
\end{abstract}

Keywords : Geoelectric; 2D and 3D model; sliding surface, water flow

\section{Pendahuluan}

Geolistrik tomografi adalah metode geofisika aktif yang dapat memberikan gambar 2D atau 3D dari distribusi resistivitas di bawah permukaan. Analisis dan interpretasi gambargambar tomogram nilai resistivitas ini memungkinkan identifikasi kontras resistivitas yang dapat dilakukan terutama karena sifat litologis dan variasi kadar air [1]. Penerapan survey geolistrik secara teoritis menyatakan bahwa kadar air di bawah permukaan memiliki korelasi positif dengan konduktifitas listrik [2]. Tomografi geolistrik dan pemodelan 2D telah digunakan dan efektif untuk mendeliniasi bidang gelincir, seperti di review oleh [2, 3], dan pemodelan $2 \mathrm{D}$ digunakan untuk identifikasi bidang gelincir dan struktur di sekitar terowongan kereta api $[4,5,6]$.

Penelitian geolistrik ini dilakukan dalam rangka mendeliniasi lapisan bawah permukaan yang sering terjadi longsor pada jalur kereta api. Longsor diduga disebabkan oleh keberadaan lapisan yang mengandung air, yang bersinggungan dengan batuan dasar, dan kemiringan lapisan yang relatif curam, sehingga saat terkenan beban, getaran kereta api di permukaan, dan fluida menyebabkan kohesifitas antar butir berkurang, sehingga lapisan di atas bergeser, hingga rel kereta api bisa berbelok dan amblas. Keberadaan lapisan pembawa longsor ini di deliniasi dengan pemodelan 2D dan 3D melalui tomografi geolistrik, dimana juga akan analisis pula arah aliran air penyebab longsor ini. 


\section{Bahan dan Metode}

Martapura-Baturaja merupakan daerah yang dilalui jalur rel kereta api LampungPalembang, dengan morfologi perbukitan bergelombang yang berada pada ketinggian antara $75-450 \mathrm{~m}$ di atas muka laut. 30\% bagian Barat wilayah ini merupakan perbukitan bergelombang dan di bagian lainnya (70\%) merupakan dataran aluvial. Morfologi wilayah Martapura merupakan perbukitan bergelombang. Dicirikan dengan adanya pebukitan membulat dengan lereng agak terjal-landai. Terbentuk oleh batuan sedimen tersier dengan ketinggian berkisar 40 meter hingga 100 meter diatas permukaan laut. Sungai-sungainya berpola aliran rektangular dan dendritik dengan lembah-lembahnya berbentuk "U" hingga bentuk "V". Memiliki tingkat erosi ke arah horisontal dan vertikal yang relatif seimbang [7].

Survei Geolistrik dilakukan pada jalur kereta api Lampung-Palembang, pada kilometer 208 yang terletak di lokasi wilayah Pusat Latihan Tempur TNI-AD Martapura-Baturaja. Bentangan lintasan survei geolistrik sejajar dengan arah rel kereta api (Tenggara-Barat Daya). Terdiri dari 2 lintasan sebelah kiri (Barat Daya) rel dan 1 lintasan diselah kanan (Timur Laut) rel. Adapun secara topografi, sebelah Barat Daya lebih rendah daripada Timur Laut rel kereta api. Target survei geolistrik adalah zona lapisan batuan keras (nilai resistansi tinggi). Lintasan survei geolistrik dapat dilihat pada Gambar 1 dan kondisi topografi di lokasi survei ditunjukan pada Gambar 2.

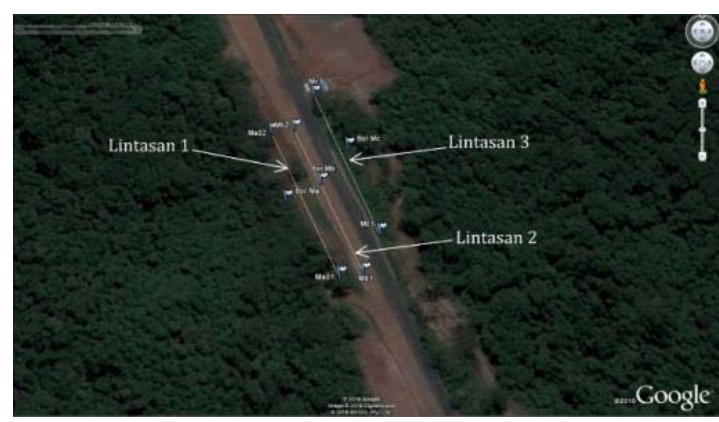

Gambar 1. Lintasan pengukuran yang terdiri dari 3 lintasan sejajar rel.

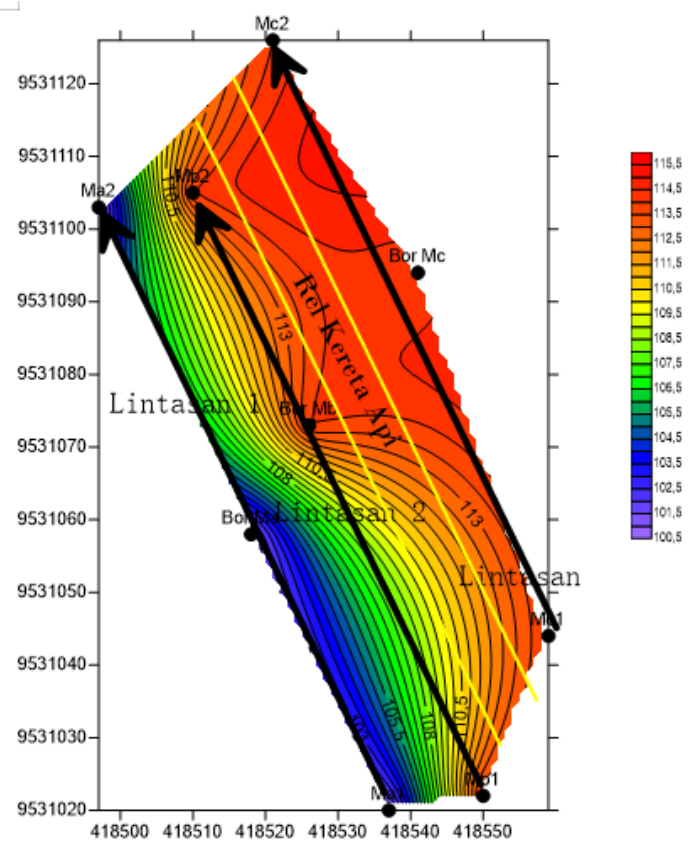

Gambar 2. Kondisi topografi lokasi survei

Pengukuran Geolistrik 2D dilakukan dengan menggunakan konfigurasi dipoledipole secara lateral. Pengukuran geolistrik 2D menggunakan 32 buah elektroda, 1 buah Switch Box, dan MultiChannel Electrode Resistivitymeter. 
Jarak antar elektroda $3 \mathrm{~m}$, sehingga panjang masing-masing lintasan $96 \mathrm{~m}$. Panjang lintasan tersebut diharapkan dapat mencapai jangkauan kedalaman $24 \mathrm{~m}$.

Pengolahan data menggunakan Software Microsoft Excel 2013, dan Software Surfer versi 12. Sedangkan pemodelan 2D menggunakan Software Res2dinv versi $3.53 \mathrm{~g}$, dan pemodelan 3D memanfaatkan Software Res3Dinv.

\section{Hasil dan Pembahasan}

Hasil pengolahan data berupa model tomogram 2D yang menggambarkan persebaran nilai resistivitas batuan secara lateral dan vertikal, sehingga menggambarkan pola perlapisan batuan berdasarkan nilai resistivitasnya. Pemodelan 3D dilakukan dengan menggabungkan model-model tomogram 2D tersebut dalam bentuk 3D, sehingga dapat menginterpretasi nilai resistivitas dari 3 lintasan 2D tersebut, pola kemiringan lapisan sehingga dapat diinterpretasi arah aliran air.

\subsection{Model Tomografi 2D}

Penampang Geolistrik secara 2D untuk masing-masing lintasan pada peta topografi hasil olahan Software Res2Dinv ditunjukan pada Gambar 3. Skala warna menunjukan distribusi nilai resistivitas secara vertikal dan horizontal.
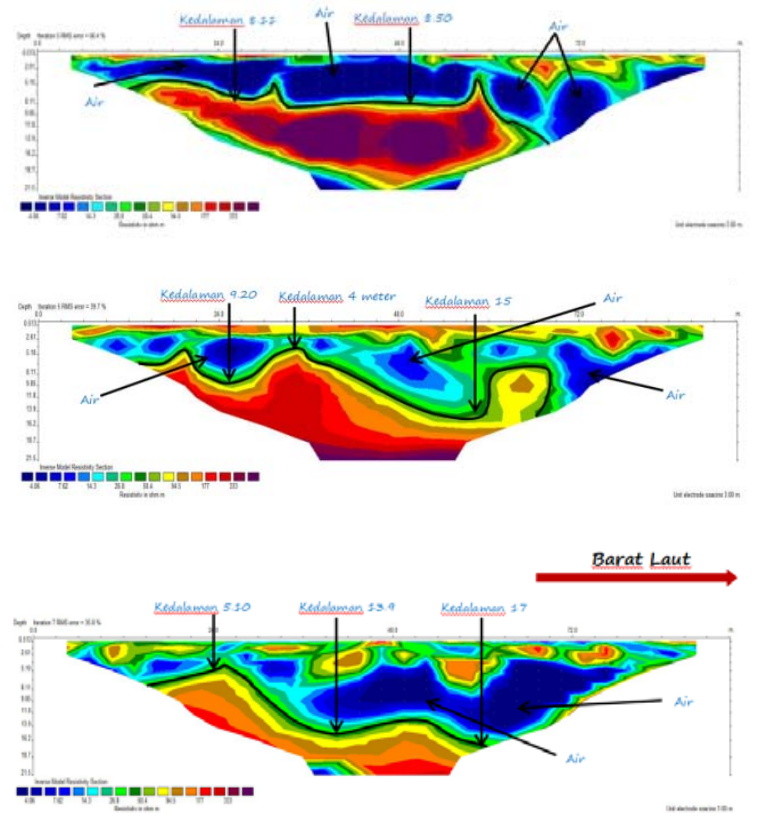

Gambar 3. Penampang geolistrik 2D hasil pengamatan pada Lintasan 1 (bawah), Lintasan 2 (tengah) dan Lintasan 3 (atas).

Warna-warna pada penampang menunjukan nilai resistivitas. Dalam penelitian ini rentang nilai resistivitas dalam hubungannya dengan litologi mengacu kepada Milsom, dkk [8], Telford, dkk [9] dan Raynold [10]. Nilai resistivitas dibagi menjadi 3 rentang nilai: (a) 4-60 ohm.m, warna biru tua sebagai resistivitas rendah, (b) 61-100 ohm.m, warna hijau sampai kuning sebagai resistivitas sedang, dan (c) 101-500 ohm.m, warna merah hingga coklat gelap, sebagai resistivitas tinggi. Pembagian nilai resistivitas berkaitan masing-masing dengan litologi dari alluvium $\left(\mathrm{Q}_{\mathrm{a}}\right)$, Formasi Kasai $\left(\mathrm{Q}_{\mathrm{TK}}\right)$ dan Formasi Muara Enim $\left(\mathrm{T}_{\mathrm{mpm}}\right)$ seperti yang dinyatakan oleh Gafoer, dkk [7] pada satuan Peta Geologi Baturaja, Sumatera. 
Nilai-nilai resistivitas ini berkaitan langsung dengan kekerasan batuan. Semakin keras batuan/tanah semakin besar pula nilai resistivitasnya menandakan semakin kecil/sedikit pori-pori batuannya, sehingga semaikin kecil pula daya tampung fluidanya. Karena semakin banyak fluida yang mengisi batuan/tanah akan menyebabkan nilai konduktivitasnya semakin tinggi, atau resistivasnya semakin rendah. Dalam hal ini, pada penampang 2D geolistrik, nilai resistivitas rendah (biru tua) menunjukan kandungan air yang semakin banyak, yakni lapisan batuan/tanah lunak. Dan sebaliknya, nilai resistivitas tinggi (coklat tua) menunjukan kandungan air yang sedikit, yakni lapisan batuan/tanah keras.

Dapat dianalisis pula bahwa perlapisan batuan dapat diperikan menjadi 3 lapisan, lapisan resistivitas relatif tinggi di dekat permukaan, lapisan resistivitas rendah dibagian tengah dan lapisan resistivitas tinggi di bagian bawah.

Lapisan yang mengandung air (resistivitas rendah) pada bagian Timur Laut lebih dangkal $(5 \mathrm{~m})$ dari pada Barat Daya $(17 \mathrm{~m})$. Kedalaman dan ketebalan lapisan mengandung air bertambah kearah Barat Laut, dan Lapisan bedrock (resistivitas tinggi) lebih dalam di bagian Barat Daya, atau Bedrock miring ke Barat Daya.

\subsection{Model Tomografi 3D}

Rekonstruksi data 3D Resistivity diperoleh dengan cara menggabungkan seluruh data 2D Resistivity ke dalam sebuah frame yang sama. Visualisasi model 3D dibuat dengan 3D Resistivity Imaging yang dibentuk dari lintasan pengukuran Geolistrik 2D yakni Lintasan 1, 2 dan 3. Model 3D untuk lapisan batuan yang mengandung air (Gambar 4) dipisahkan dari lapisan batuan keras (Gambar 5).

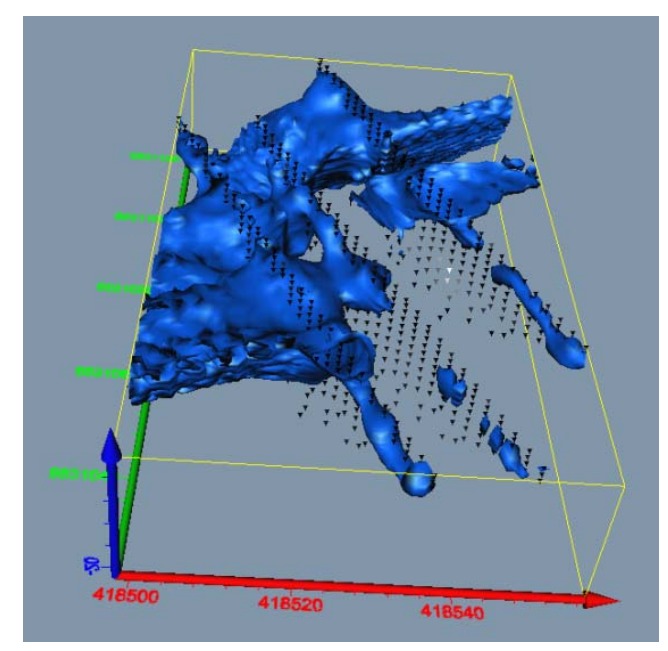

Gambar 4. Rekonstruksi 3D Lapisan Batuan yang mengandung Air Hasil Geolistrik.

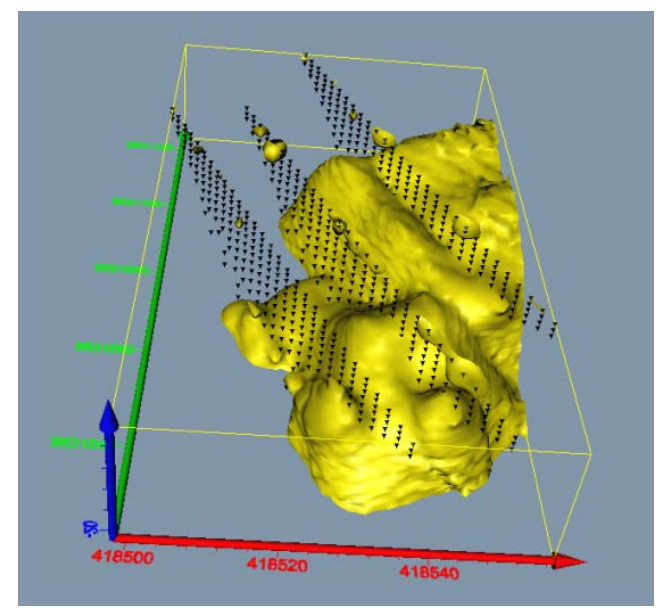

Gambar 5. Rekonstruksi 3D Lapisan batuan keras (bedrock) Hasil Geolistrik 
Berdasarkan rekonstruksi data 3D Geolistrik pada lintasan 1 hingga lintasan 3, menjelaskan bahwa arah aliran air diidentifikasi pada nilai resistivitas di antara 4 Ohm.m - 60 Ohm.m (diindikasikan oleh lapisan berwarna biru dan hijau) yang berkorelasi dengan Formasi Kasai. Sedangkan pada lapisan batuan keras (bedrock) diidentifikasikan pada nilai resistivitas di antara 100 Ohm.m - 500 Ohm.m.

\subsection{Model Aliran Air}

Arah aliran air dapat diketahui dengan cara menggabungkan model 3D lapisan batuan yang memiliki nilai resistivitas rendah dan yang tinggi dalam satu frame (Gambar 6). Dari penggabungan tersebut terlihat bahwa lapisan batuan yang mengandung air (warna biru) terkonsentrasi di bagian Barat - Barat Daya dan menipis di bagian Utara - Timur Laut. Warna biru semakin dalam di bagian Barat Daya. Dengan demikian, sesuai dengan kenyataan bahwa air akan mengalir dari yang tinggi ke yang lebih dalam. Sehingga aliran air dapat diinterpretasi mengalir dari Timur Laut menuju Barat Daya.

Aliran air yang bergerak pada lapisan bagian atas yang berbatasan dengan bedrock yang keras, yang diduga sebagai hypothetical sliding surface [3]. Pada batas lapisan ini, air akan menyebabkan ikatan antara lapisan dengan nilai resistivitas rendah dan tinggi menjadi lemah. Apabila akumulasi air yang terkandung dalam palisan batuan yang lunak melebihi kapasitas jenuh, maka massa batuan lubak yang berada di atas bidang gelincir akan longsor ke arah Barat Daya.

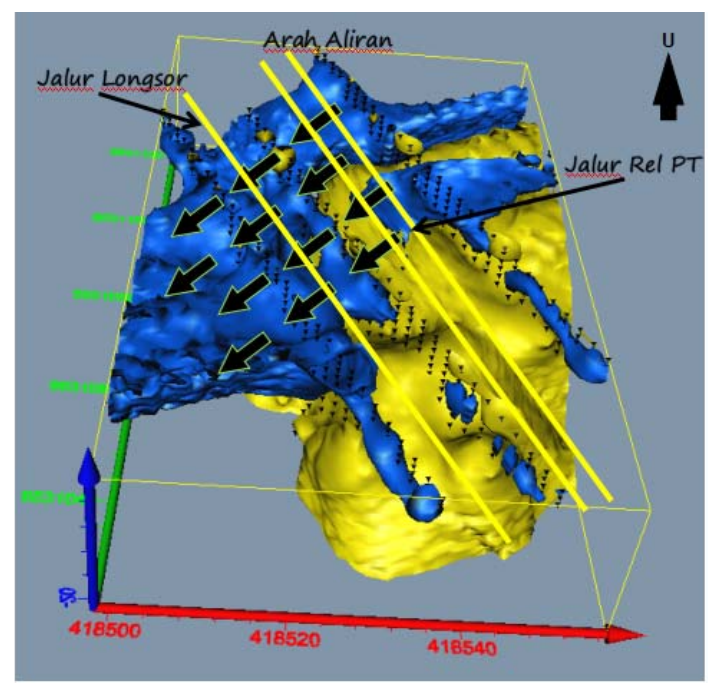

Gambar 6. Rekonstruksi geolistrik 3D menungjukkan arah aliran air yang menyebabkan longsor.

\section{Kesimpulan}

Ada 3 lapisan tanah/batuan di bawah permukaan yang dapat dicitrakan berdasarkan nilai resistivitas secara geolistrik, yaitu lapisan keras yang berkorelasi dengan nilai resistivitas tinggi di bagian atas dan bawah dan lapisan lunak yang berkorelasi dengan nilai resistivitas rendah. Berdasarkan pemodelan data geolistrik 2D lapisan yang diduga mengandung air atau dialiri air berkisar pada nilai resistivitas di antara $4 \Omega \mathrm{m}$ $60 \Omega \mathrm{m}$ dan pada lapisan batuan keras (bedrock) diidentifikasikan pada nilai resistivitas di antara $100 \Omega \mathrm{m}$ hingga 500 $\Omega \mathrm{m}$.

Berdasarkan pemodelan rekonstruksi air 
geolistrik 3D, maka didapatkan arah aliran air dari arah Timur Laut ke arah Barat Daya, dimana arah longsoran atau pergerakan tanah (landslide) mengikuti pola aliran air ini.

\section{Ucapan Terima Kasih}

Penulis mengucapkan terima kasih kepada PT. KAI dan PT LGS atas kesempatan menggunakan data ini sehingga dapat dijadikan tulisan ilmiah.

\section{Referensi}

1. Abidin, M.H. B., Saad, R.B., Ahmad, F. B., Wijeyesekera, D.C., Baharuddin, M.F. B. (2012). Integral Analysis of Geoelectrical (Resistivity) and Geotecnical (SPT) Data in Slope Stability Assessment. Academic Journal of Science. 1(2):305-316.

2. Perone, A., Lappena, V., Piscitelli, S., Electrical Resistivity Tomography Technique for Landslide Investigation: a review. Earth-Science Review 135 (2014) 65-82.

3. Colangelo, G., Lapenna, V., Loperte, A., Perrone, A., Telesca, L. (2008). 2D Electrical Resistivity Tomographies for Investigating Recent Activation Landslides in Basilicata Region (Southern Italy). Annals of Geophysics, 51(1): 275-285.

4. Ardi, N.D and Iryanti, M, AIP Conference Proceedings 1708, 070001

(2016); https://
5. Singh, Y., Sharma, V., Pandita, S.k., Bhati, G.M., Thakur, K.K., dan Kotwali, S.S., Investigation of Landslide at Sangaldan Near Tunnel47, on Katra- Qazigund Railway Track, Jammu and Kashmir, JOURNAL GEOLOGICAL SOCIETY OF INDIA, Vol.84, December 2014, pp.686-692.

6. A. Susilo, Sunaryo, and Wasis, Subsurface Structure Prediction of Railroad

Tunnel in Malang, Indonesia Based on Dipole-Dipole Geoelectrical Method, Journal of Traffic and Logistics Engineering, Vol, 1, No. 2 December 2013

7. Gafoer, S., Amin, T.C., and Pardede, R., 1993. Geological Map of Baturaja Quadrangle, Sumatra, Scale 1 : 250.000. Geological Research and Development Centre, Bandung.

8. Milsom, J., 2003, Field Geophysics $3^{\text {rd }}$ Edition, p. 83-91.

9. Telford, W.M., Geldart, L.P., dan Sheriff, R.E., 1990, Applied Geophysics $2^{\text {nd }}$ Edition, p. 283-293.

10. Reynolds, J.M., An Introduction to Applied and Environmental Geophysics, John Wiley \& Sons, pp. 415-522. 